\title{
Modified Limiting Equilibrium Method for Stability Analysis of Stratified Rock Slopes
}

\author{
Rui Yong, ${ }^{1}$ Chang-Dong Li, ${ }^{2}$ Jun Ye, ${ }^{1}$ Man Huang,, and Shigui Du ${ }^{1,2}$ \\ ${ }^{1}$ Key Laboratory of Rock Mechanics and Geohazards, Shaoxing University, Zhejiang, Shaoxing 312000, China \\ ${ }^{2}$ Engineering Faculty, China University of Geosciences, Wuhan, Hubei 430074, China \\ Correspondence should be addressed to Shigui Du; dsg@usx.edu.cn
}

Received 15 May 2016; Revised 24 July 2016; Accepted 30 August 2016

Academic Editor: Jose J. Muñoz

Copyright (c) 2016 Rui Yong et al. This is an open access article distributed under the Creative Commons Attribution License, which permits unrestricted use, distribution, and reproduction in any medium, provided the original work is properly cited.

\begin{abstract}
The stratified rock of Jurassic strata is widely distributed in Three Gorges Reservoir Region. The limit equilibrium method is generally utilized in the stability analysis of rock slope with single failure plane. However, the stratified rock slope cannot be accurately estimated by this method because of different bedding planes and their variable shear strength parameters. Based on the idealized model of rock slope with bedding planes, a modified limiting equilibrium method is presented to determine the potential sliding surface and the factor of safety for the stratified rock slope. In this method, the S-curve model is established to define the spatial variations of the shear strength parameters $c$ and $\varphi$ of bedding plane and the tensile strength of rock mass. This method was applied in the stability evaluation of typical stratified rock slope in Three Gorges Reservoir Region, China. The result shows that the factor of safety of the case study is 0.973 , the critical sliding surface for the potential slip surface appears at bedding plane $\mathrm{C}$, and the tension-controlled failure occurs at $10.5 \mathrm{~m}$ to the slope face.
\end{abstract}

\section{Introduction}

The analysis for the estimation of rock slope stability has been a challenging task for engineers in civil and mining engineering $[1,2]$. Rock masses constituting the slopes often have discontinuities (jointing and bedding patterns) and free space/excavation surfaces in various forms, resulting in different types of slope failures [3,4]. Planar failure is one of the most common rock slope failure modes that happened in stratified rock masses [5-7]. The stratified structure of a rock mass is typically acquired during sedimentary deposition, and planar structures such as foliation or schistosity can also be produced by metamorphism. This process can cause differences in material composition, particle size, and fabric or mineral orientation that result in rock stratification $[8,9]$. The dips and mechanical parameters of the bedding planes in naturally stratified rock masses have stronger influences on rock mass strength and stability. Therefore, the appraisal of slope stability in stratified rock masses is complicated because dominant discontinuities lead to a highly anisotropic behavior [10]. The potential sliding surfaces in stratified rock masses should be considered in determining the critical sliding surface and the stability of rock slope. However, the previous studies on planar failure were mainly focused on the stability of rock slopes with a single failure plane, and they are not capable of analyzing the rock slope with various bedding planes.

The limit equilibrium method for the estimation of the factor of safety (FS) of the rock slope against plane failure has been widely accepted by the engineers, mainly because of its validity and simplicity. Hoek and Bray [11] presented an analytical solution for the plane failure mode in rock slopes, in which the upper slope surface and tension crack were assumed to be horizontal and vertical, respectively. Based on this research, Sharma et al. [12] extended the plane failure analysis to incorporate an inclined upper slope and a nonvertical tension crack. Kroeger [13] illustrated the plane failure analyses of compound slopes by limit equilibrium approach and proposed new equations for determining tension cracks. Jiang et al. [14] proposed different limiting equilibrium approaches for computing the stability of the planar failure rock slope. Ahmadi and Eslami [15] explored the effects of 
the forces due to water pressure on discontinuity surface in plane failure rock slope. However, these methods are restricted by the requirement that single valued parameters describe the slope characteristics [16]. In actuality, the shear strength of a rock mass is spatially variable due to the factors like climate, carbonation, geology, relief, vegetation cover, or human activities. For instance, some slopes may be composed of rocks which have been extensively and deeply weathered in situ over long periods [17]. The strength of rock mass near the slope surface and upper slope surface is easily affected by these factors, but less influence on the deeper inside of the rock mass. Obviously, we cannot neglect the strength variations along the sliding surface which may affect the accuracy of slope stability calculations by the limit equilibrium method. However, this inherent variability of shear strength has often been portrayed in an oversimplified way in earlier researches on rock slope instability.

The objectives of this paper are (1) to present a mathematical model for describing the spatial variations of the shear strength rock discontinuities and tension strength of rock mass, (2) to propose calculation procedure for determining the critical sliding surface and tension crack, and (3) to introduce a method for evaluating the stability of the stratified rock slope. Furthermore, this modified limiting equilibrium method was applied to the stability assessment of the case study, Jiaxiao Slope, in Three Gorges Reservoir Region, China.

\section{Calculation Method and Model}

2.1. Geomechanical Model. Planar rock slope failure occurs when a rock mass in a slope slides down and along a relatively planar failure surface. These failure surfaces are usually structural discontinuities, such as bedding planes, faults, joints, or the interface between bedrock and an overlying layer of weathered rock. Stability condition occurs if the critical joint dip is less than the slope angle, and mobilized joint shear strength is not enough to assure the stability of the slope.

The planar failure mode provides insightful knowledge on the behavior of rock slopes, in which the material above this surface is regard as a "free body." The disturbing and resisting forces are estimated enabling the formulation of equations concerning force or moment equilibrium (or both) of the potential sliding mass. FS is defined as the ratio of resisting forces to driving forces.

Let us consider a slope of inclination $i$, height $H$, and a potential failure plane of inclination $\beta$ (Figure 1). According to the geometric properties in Figure 1, the weight of the rigid block $A B C$ is calculated by

$$
\begin{aligned}
h & =\frac{H}{\sin i} \sin (i-\beta), \\
L & =\frac{H}{\sin \beta}, \\
G & =\frac{1}{2} \rho g h L=\frac{\rho g H^{2} \sin (i-\beta)}{2 \sin i \cdot \sin \beta},
\end{aligned}
$$

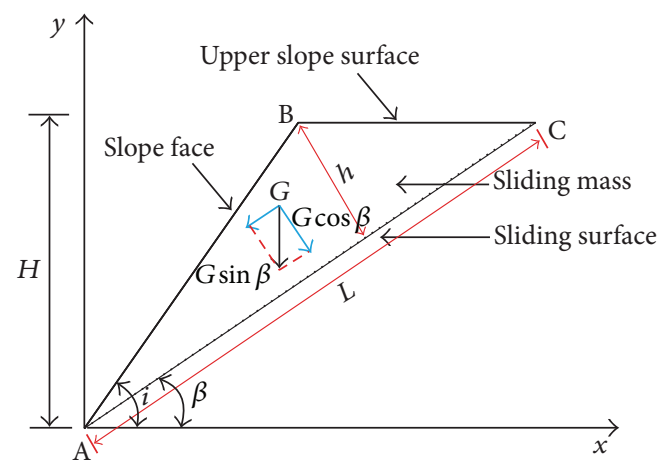

FIgURE 1: A rock slope in plane failure.

where $\rho$ is the average density of the rock mass; $g$ is the gravitational acceleration $\left(9.8 \mathrm{~m} / \mathrm{s}^{2}\right) ; L$ is the length of the failure plane AC. It is easy to obtain the driving force $F_{r}$ and resisting force $F_{s}$ by the force analysis of the rigid block $A B C$,

$$
\begin{aligned}
& F_{s}=G \cos \beta \tan \varphi+c L, \\
& F_{r}=G \sin \beta,
\end{aligned}
$$

where $\varphi$ and $c$ are the effective internal friction angle and cohesion of failure plane. The factor of safety (FS) can be obtained by the force equilibrium equation as follows:

$$
\begin{aligned}
\mathrm{FS} & =\frac{F_{s}}{F_{r}}=\frac{G \cos \beta \tan \varphi+c L}{G \sin \beta} \\
& =\frac{2 c \sin i}{\rho g H \sin (i-\beta) \sin \beta}+\frac{\tan \varphi}{\tan \beta} .
\end{aligned}
$$

This model is widely used in planar rock slope failure analysis, which offers considerable insights into the behavior of real slopes. However, it failed to be utilized for the stability analyzing of the stratified rock slope with series of bedding planes. Then, the shear strength parameters $\varphi$ and $c$ along the failure plane were treated as constant values, which failed to reflect the strength variations along the sliding surface. Furthermore, the potential failure rock mass was commonly assumed as a rigid block, so the potential tensile failure cannot be considered in the planar rock slope failure analysis.

The sliding mass of stratified rock slope can be divided into several plane segments by rock bedding surfaces (Figure 2). However, it is hard to find the slip surface from these bedding surfaces, geological discontinuities, and surfaces of weakness. The limit equilibrium analysis method was extended for determining the critical position in all the potential slip surfaces. Here, the exposed length of each layer $i$ on the upper ground surface is labeled by $L_{a i}$. The exposed length on the slope face is denoted as $L_{b i}$. The potential tension crack appears on the upper slope surface, and its horizontal distance to slope face is $L_{c}$. The tensile strength of sliding mass is considered in this idealized model, because the rock mass may have a tensile failure and create the tensile crack in some conditions (e.g., the shear strength of most of the sliding surface is very low but reaches high value near upper slope surface). Furthermore, the field investigations 


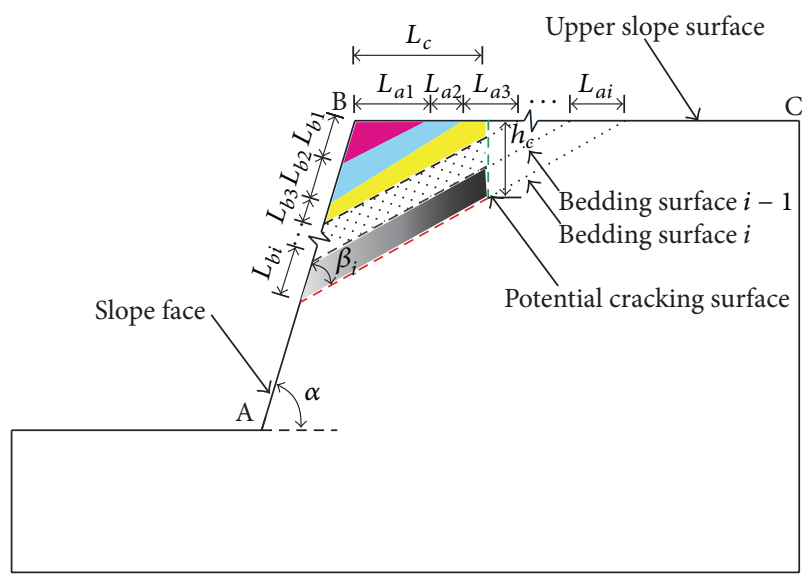

FIGURE 2: Idealized model of rock slope with bedding planes.

indicate that the cohesion $c$ and friction angle $\varphi$ of bedding surfaces are variable at different slip surfaces. As common sense, the shear strength of the rock discontinuities near to slope surface is usually lower than that in the deep place. Due to the anisotropy of shear strength, it is no longer reasonable to simplify the bedding rock slope failure by the planar rock slope mode in Figure 1.

Furthermore, in the idealized model of stratified rock slope, the locations of the bedding planes are determined based on the exposed length $L_{a i}$ of each layer on the upper ground surface and the exposed length $L_{b i}$ on the slope face. However, there is a challenge in the pairing up of the daylight locations for a potential slip plane on the top boundary and slope face, because sometimes the exposed length $L_{b i}$ on the slope face is difficult to measure, especially for those slopes with large slope angles. In rock engineering practices, the geotechnical drilling is suggested to be implemented at different positions on the upper surface of rock slope. Based on the core samples from drilling tubes, the dip angles of the bedding planes can be obtained via measuring the dip angles of the bedding planes. Generally, the potential failure surface is assumed to be planar in planar rock slope failure analysis. Then, the corresponding exposed length $L_{b i}$ on the slope surface can be calculated through daylight location on the top boundary and dip angle of the bedding plane.

2.2. Basic Assumptions. Comparing the single planar failure model with the idealized model of bedding rock slope, it is necessary to make a few assumptions for the stability assessment. The main assumptions are summarized as follows:

(1) It is assumed that the slope face, upper slope surface, failure plane, and the tension crack are parallel or nearly parallel. The rock slope has a vertical tension crack, and the upper surface of the slope is horizontal.

(2) The assumed failure mode is translational-crack-slip and the sliding block is assumed to have a unit thickness in the planar failure analysis.

(3) Release or free surfaces are present, parallel to the cross section of the analysis, which provides negligible

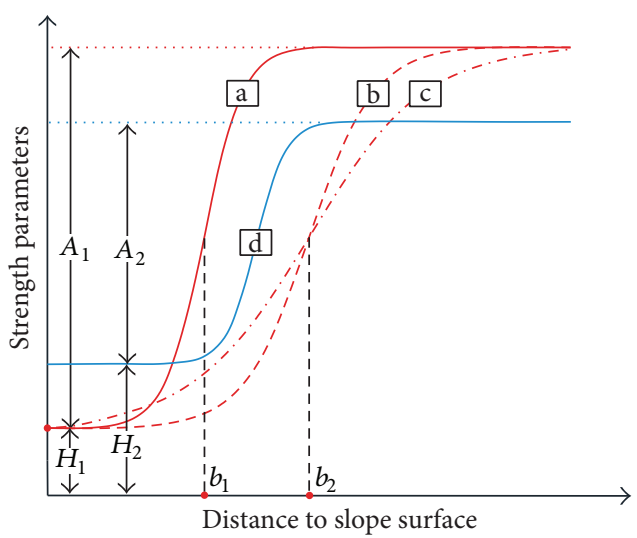

FIGURE 3: Relationship between strength parameters and distance to slope surface.

or no resistance to sliding at the lateral boundaries of the failure.

(4) The tensile strength $\sigma$ of the rock mass and shear strength parameters $c$ and $\varphi$ of rock discontinuities are assumed to be anisotropic, and the spatial variation model of strength parameters is provided in Section 2.3.

(5) The above assumptions represent rock block sliding along a single joint which is the potential slip surface in the rock mass, and there is no relative sliding between different bedding planes above the slip surface. The shear force over the slip surface is determined by Mohr-Coulomb criterion here.

2.3. Spatial Variation Model for Rock Mass and Rock Discontinuities. The spatial variability of rock discontinuities shear strength parameters $c$ and $\varphi$ and the rock mass tensile strength $\sigma$ is considered in this idealized model of bedding rock slope. S-curve model belongs to multiple variable analysis methods and mainly appears in logit model or logistic regression model. It is widely used in the statistical and empirical analysis in fields like sociology, biostatistics, clinical medicine, marketing management, and so forth. S-curve model has the basic features for describing the progressive transition from one value to another which increases nonlinearly and continuously, whose variation trend is shaped like "S" (Figure 3). In previous studies, the S-curve model has been used successfully in describing the spatial variations of the shear strength parameters of the bedding plane $[8,18,19]$. There are real data supporting the validity of the S-curve model and this model has been successfully used to describe the spatial variations of the shear strength parameters caused by the weakening effects. Based on the S-curve model, some suggested methods were proposed for analyzing the stability of rock slope with bedding surfaces. Here, it is appropriate to illustrate the variations of the strength, including shear strength parameters $c$ and $\varphi$ of rock discontinuities and the rock mass tensile strength $\sigma$. 
According to S-curve model, the strength can be expressed as follows:

$$
S(x)=\frac{A}{1+e^{-c^{\prime}(x-b)}}+H^{\prime}
$$

where $S(x)$ denotes the strength of rock mass or rock discontinuities; $x$ is the distance to the slope surface; $H^{\prime}$ is the lowest strength of rock mass or rock discontinuities. The strength of rock mass or rock discontinuities deep inside the rock slope is barely affected by the factors mentioned above, so it gets the largest value. $A$ is the difference between the lowest and the largest strength. The comparison between curves (a) and (d) in Figure 3 shows that the variation of lowest and largest value in S-curve model is determined by coefficients $A$ and $H^{\prime} ; b$ and $c^{\prime}$ are the shape controlling factors of S-curve model. Then $b$ represents the distance to the slope surface when the strength is equal to the mean value of the lowest and the highest strength, and $c^{\prime}$ is positively correlated with the inverse of $b$.

In the present study, the S-curve model is established to define the spatial variations of the shear strength parameters of bedding plane and the tensile strength of rock mass. For the shear strength parameters, $H^{\prime}$ is the shear strength of highly weathered rock discontinuities near slope surface; $A$ is the difference between the shear strength value of the highly weathered rock discontinuities and the highest shear strength value of discontinuities which are the least affected by weathering effect; $b$ and $c^{\prime}$ are obtained by curvefitting of the shear strength of the rock discontinuities and the locations of rock joint specimens. For tensile strength parameters, $H^{\prime}$ is the tensile strength of rock specimens near slope surface; $A$ is acquired by calculating the difference between $H^{\prime}$ and the tensile strength of intact rock specimen; based on the variable tensile strength and the depth of rock specimens, $b$ and $c^{\prime}$ values are acquired through the $\mathrm{S}$-curve model fitting.

It is assumed that the shear strength parameters are associated with the distance to slope surface. The distances between upper slope surface and slope face have the same influence on the shear strength parameters. A set of equations for describing shear strength parameters $c$ and $\varphi$ along the bedding surface are illustrated as follows:

$$
\varphi(x)= \begin{cases}\frac{A_{\varphi}}{1+e^{-c_{\varphi}\left(x-b_{\varphi}\right)}}+H_{\varphi}, & \left(x \leq \frac{L_{i}}{2}\right), \\ \frac{A_{\varphi}}{1+e^{-c_{\varphi}\left(L_{i}-x-b_{\varphi}\right)}}+H_{\varphi}, & \left(\frac{L_{i}}{2} \leq x \leq s_{i}\right),\end{cases}
$$

$$
c(x)= \begin{cases}\frac{A_{c}}{1+e^{-c_{c}\left(x-b_{c}\right)}}+H_{c}, & \left(x \leq \frac{L_{i}}{2}\right), \\ \frac{A_{c}}{1+e^{-c_{c}\left(L_{i}-x-b_{c}\right)}}+H_{c}, & \left(\frac{L_{i}}{2} \leq x \leq s_{i}\right),\end{cases}
$$

where $H_{\varphi}$ and $H_{c}$ are the shear strength of rock discontinuities near slope surface, and they are the lowest shear strength parameters; the shear strengths of new and complete rock discontinuities reach the largest value; $A_{\varphi}$ and $A_{c}$ are the differences between the lowest and largest shear strength parameters; $b_{\varphi}, b_{c}, c_{\varphi}$, and $c_{c}$ are the shape controlling coefficients of equation set. These coefficients can be obtained by direct shear tests on the specimens taken from different parts of bedding surface. In Figure $4, L_{i}$ is the length of bedding surface, and $s_{i}$ is the length of the potential sliding surface which is controlled by the cracking surface.

Similarly, tensile strength based on the S-curve model can be expressed as

$$
\sigma(h)=\frac{A_{\sigma}}{1+e^{-c_{\sigma}\left(h-b_{\sigma}\right)}}+H_{\sigma},
$$

where $H_{\sigma}$ is the lowest tensile strength of rock mass on the slope surface; $A_{\sigma}$ is the difference between the lowest and largest tensile strength; $b_{\sigma}$ and $c_{\sigma}$ are the shape controlling coefficients of tensile strength change function; $h$ is the depth from the upper slope surface to the intersection of bedding surface and cracking surface (Figure 5). In this study, the potential vertical tensile cracks are assumed to appear when the sliding happens. The influence on the distributions of the cohesion and frictional angle in tensile crack developing was not considered here.

2.4. Modified Limiting Equilibrium Equations. The rock mass above the failure surface is regarded as an entire sliding body, and the back geometric boundary is the potential cracking surface (Figure 6). Here, the bedding surface $i$ is the failure surface.

The length of bedding surface $i$ can be described by

$$
\begin{aligned}
& L_{i} \\
& =\sqrt{\left[\left(\sum_{k=1}^{i} l_{b k}\right) \cdot \cos \alpha+\left(\sum_{k=1}^{i} l_{a k}\right)\right]^{2}+\left[\left(\sum_{k=1}^{i} l_{b k}\right) \cdot \sin \alpha\right]^{2}} .
\end{aligned}
$$

The failure plane dip is

$$
\beta_{i}=\arcsin \left(\frac{\sum_{k=1}^{i} l_{b k} \cdot \sin \alpha}{\sqrt{\left[\left(\sum_{k=1}^{i} l_{b k}\right) \cdot \cos \alpha+\left(\sum_{k=1}^{i} l_{a k}\right)\right]^{2}+\left[\left(\sum_{k=1}^{i} l_{b k}\right) \cdot \sin \alpha\right]^{2}}}\right) .
$$




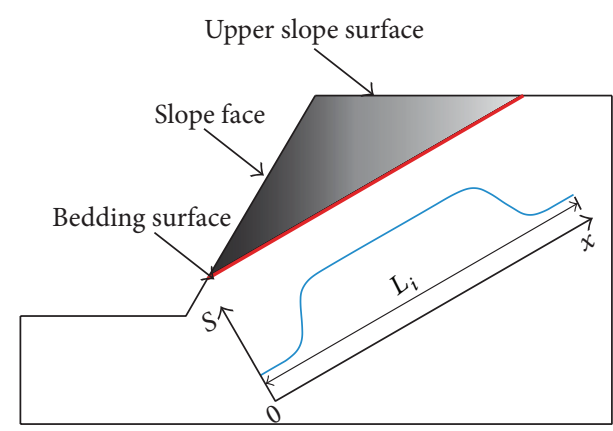

(a)

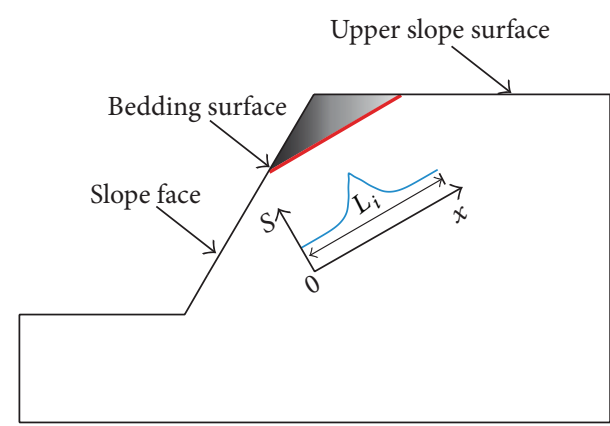

(c)

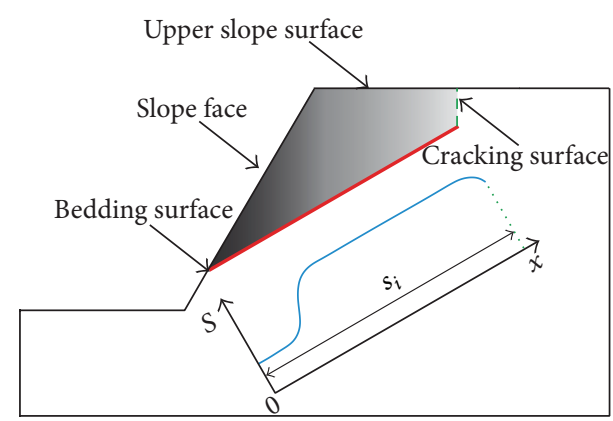

(b)

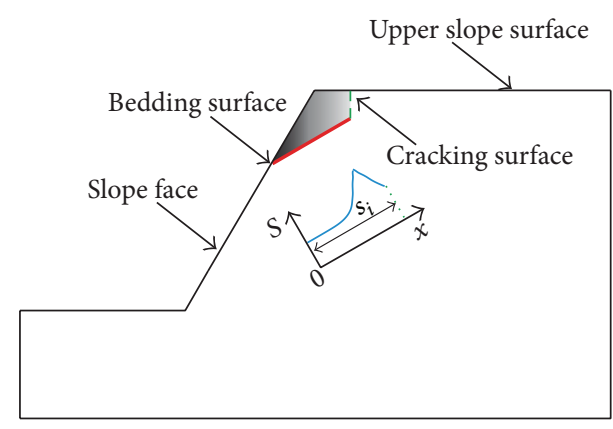

(d)

FIGURE 4: Relationships between shear strength $S$ of bedding surface and distance $x$ to slope surface: (a) long bedding plane without cracking surface, (b) long bedding plane with cracking surface, (c) small bedding plane without cracking surface, and (d) short bedding plane with the cracking surface. as

The length of potential cracking surface can be expressed

$$
h_{c}=\frac{\left[\left(\sum_{i=0}^{k} l_{a i}\right)-l_{c}\right] \cdot\left(\sum_{i=0}^{k} l_{b i}\right) \cdot \sin \alpha}{\left(\sum_{i=0}^{k} l_{a i}\right)+\left(\sum_{i=0}^{k} l_{b i}\right) \cdot \cos \alpha} .
$$

The length of failure surface is

$$
\begin{aligned}
s_{i} & =\left(1-\frac{\left(\sum_{k=1}^{i} l_{a k}\right)-l_{c}}{\left(\sum_{k=1}^{i} l_{a k}\right)+\left(\sum_{k=1}^{i} l_{b k}\right) \cdot \cos \alpha}\right) \\
& \cdot \sqrt{\left[\left(\sum_{k=1}^{i} l_{b k}\right) \cdot \cos \alpha+\left(\sum_{k=1}^{i} l_{a k}\right)\right]^{2}+\left[\left(\sum_{k=1}^{i} l_{b k}\right) \cdot \sin \alpha\right]^{2}} .
\end{aligned}
$$

The weight of sliding mass is

$$
\begin{aligned}
G_{i} & =\rho \cdot g \cdot\left[\frac{1}{2}\left(\sum_{k=1}^{i} l_{a k}\right) \cdot\left(\sum_{k=1}^{i} l_{b k}\right) \cdot \sin (\alpha)-\frac{1}{2} h_{c}\right. \\
& \left.\cdot\left(\left(\sum_{k=1}^{i} l_{a k}\right)-L_{c}\right)\right] .
\end{aligned}
$$

The resistance supplied by the tensile strength of rock mass can be written as

$$
T_{i}=\int_{0}^{h_{c}} w\left(\sigma_{t}\right) d h .
$$
by

The normal force on the failure surface can be obtained

$$
N_{i}=G_{i} \cdot \cos \beta_{i}+T_{i} \cdot \sin \beta_{i}
$$

The resistance supplied by the cohesion of the bedding surface is

$$
\begin{aligned}
P(x)= & \int_{0}^{L_{i} / 2}\left(\frac{A_{c}}{1+e^{-c_{c}\left(x-b_{c}\right)}}+H_{c}\right) d x \\
& +\int_{L_{i} / 2}^{s_{i}}\left(\frac{A_{c}}{1+e^{-c_{c}\left(L_{i}-x-b_{c}\right)}}+H_{c}\right) d x .
\end{aligned}
$$

The average friction coefficient of the bedding surface is

$$
\begin{gathered}
\overline{f(x)}=\frac{1}{s_{i}}\left[\int_{0}^{L_{i} / 2} \tan \left(\frac{A_{\varphi}}{1+e^{-c_{\varphi}\left(x-b_{\varphi}\right)}}+H_{\varphi}\right) d x\right. \\
\left.+\int_{L_{i} / 2}^{s_{i}} \tan \left(\frac{A_{\varphi}}{1+e^{-c_{\varphi}\left(L_{i}-x-b_{\varphi}\right)}}+H_{\varphi}\right) d x\right] .
\end{gathered}
$$

The factor of safety $\eta$ can be obtained by

$$
\eta=\frac{F_{s i}}{F_{r i}}=\frac{N_{i} \cdot \overline{f(x)}+P(x)}{G_{i} \cdot \sin \beta_{i}-T_{i} \cdot \cos \beta_{i}},
$$

where $F_{s i}$ is the resisting force and $F_{r i}$ is the driving force of this bedding plane. 


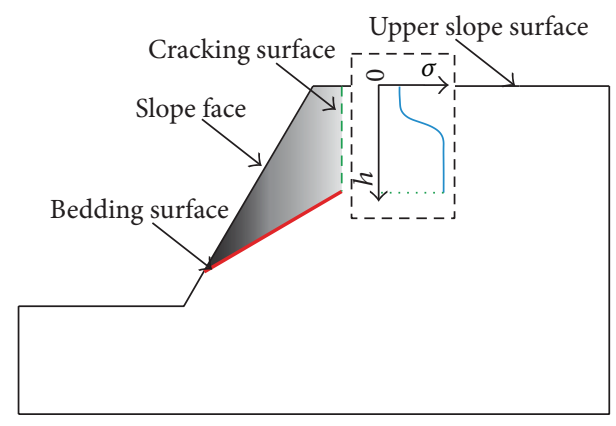

FIGURE 5: Relationships between tensile strength $\sigma$ of rock mass and distance $h$ to upper slope surface.

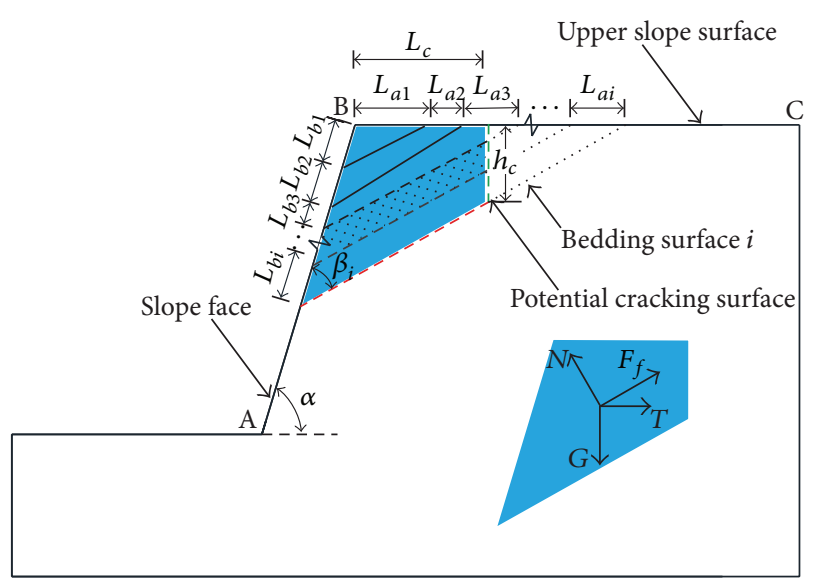

FIGURE 6: Computing model of bedding rock slope.

The critical sliding surface can be determined by finding the potential sliding surface which has the minimum factor of safety. The stability analysis was taken by performing series of iterations on various combinations of potential sliding surface and tensile crack. The flow chart for evaluating the stability of the stratified rock slope is shown in Figure 7.

\section{A Case Study by Modified Limiting Equilibrium Method}

3.1. Introduction of the Jiaxiao Slope. Jiaxiao Slope is a typical bedding rock slope in Triassic Strata, which is situated at Jingmen City, Hubei Province, China. The slope is mainly composed of weathered sandstone. There are three bedding surfaces, namely, bedding plane $\mathrm{A}$, bedding plane $\mathrm{B}$, and bedding plane $\mathrm{C}$ (Figure 8). The dip of bedding plane is approximately $22^{\circ}$. The upper slope surface is nearly horizontal, and the slope height is about $12 \mathrm{~m}$. The sandstone crushing degree is controlled by the depth to slope surface, which severely influences the strength of rock mass and discontinuities.

A geotechnical investigation was carried out in June 2013 which included the drilling of six geotechnical drill holes on the upper surface of Jiaxiao Slope. Then, based on the drill cores, we obtained six rock samples for the tensile strength test and nine rock joint samples for the shear strength test.
The tensile specimens are disc-shaped with a diameter $D=$ $50 \mathrm{~mm}$ and a thickness $t=25 \mathrm{~mm}$ and the sizes of the rock joint samples are about $80 \mathrm{~mm} \times 80 \mathrm{~mm}$. Here, the Brazilian test was performed to determine the indirect tensile strength according to ISRM (1978) [20]. The test result shows that the tensile strength of highly weathered rock specimens near slope surface is $0.3 \mathrm{MPa}$, and the tensile strength of intact rock specimen is $4.8 \mathrm{MPa}$. Thus, it is obvious that $H_{\sigma}=0.3 \mathrm{MPa}$ and $A_{\sigma}=4.5 \mathrm{MPa}$ in the S-curve model (Figure 9), and the $\mathrm{S}$-curve model for the tensile strength can be written as

$$
\sigma(h)=\frac{4.5}{1+e^{-c_{\sigma}\left(h-b_{\sigma}\right)}}+0.3
$$

Similarly, based on the direct shear test for joint specimens, the friction angle and cohesion of highly weathered rock discontinuities near slope surface are $11.00^{\circ}$ and $0.19 \mathrm{MPa}$. The friction angle and cohesion of the unweathered rock discontinuities are $18.70^{\circ}$ and $0.28 \mathrm{MPa}$. According to the S-curve model fitting result (Figure 10), the S-curve models for shear strength in (5) can be written as

$$
\begin{aligned}
& \varphi(x) \\
& \quad= \begin{cases}\frac{7.70}{1+e^{-14.40(x-0.10)}+11,} & \left(x \leq \frac{L_{i}}{2}\right), \\
\frac{7.70}{1+e^{-14.40\left(L_{i}-x-0.10\right)}+11,} & \left(\frac{L_{i}}{2} \leq x \leq s_{i}\right),\end{cases} \\
& c(x) \begin{array}{ll}
\frac{0.09}{1+e^{-23.00(x-0.1)}}+0.19, & \left(x \leq \frac{L_{i}}{2}\right), \\
\frac{0.09}{1+e^{-23.00\left(L_{i}-x-0.1\right)}+0.19,} & \left(\frac{L_{i}}{2} \leq x \leq s_{i}\right) .
\end{array}
\end{aligned}
$$

The strength coefficients of bedding plane and rock mass are tabulated in Table 1. Moreover, the shear strength of bedding rock joints was obtained by the direct shear test. The average unit weight $\gamma$ is $28 \mathrm{kN} / \mathrm{m}^{3}$.

3.2. Stability Analyses on the Case Study. The stability of this bedding rock slope was calculated by the modified limiting equilibrium method presented above. The distributions of safety factor $\eta$ of three bedding planes are illustrated in Figure 11. The $\eta$ values of each bedding plane decline first and tend to be stable later. However, in the stable section, each bedding plane's $\eta$ firstly decrease and then increase a little bit. Most of the safety factors of bedding plane B are larger than those of bedding plane A and bedding plane $\mathrm{C}$. Moreover, the safety factor of bedding $\mathrm{A}$ is larger than the safety factor of bedding $\mathrm{C}$ when $L_{c}$ is shorter than $3 \mathrm{~m}$. The minimum $\eta$ of bedding plane $\mathrm{A}$ is 1.012 , the minimum $\eta$ of bedding plane B is 1.071 , and the minimum $\eta$ of bedding plane $\mathrm{C}$ is 0.973 . Therefore, the critical sliding surface is bedding plane $\mathrm{C}$, which has the minimum $\eta$ of the bedding rock slope. Moreover, the result shows that the potential tensioncontrolled failure would be most likely to occur at $10.5 \mathrm{~m}$ to the slope face. 
TABLE 1: Strength coefficients of bedding plane and rock mass (MPa).

\begin{tabular}{|c|c|c|c|}
\hline \multirow{2}{*}{ Coefficient of strength function } & \multicolumn{2}{|c|}{ Bedding plane } & \multirow{2}{*}{$\begin{array}{c}\text { Rock mass } \\
\text { Tensile strength }\end{array}$} \\
\hline & Friction angle $\left({ }^{\circ}\right)$ & Cohesion (MPa) & \\
\hline$H$ & 11.00 & 0.19 & 0.30 \\
\hline$A$ & 7.70 & 0.09 & 4.50 \\
\hline$c$ & 14.40 & 23.00 & 4.18 \\
\hline$b$ & 0.10 & 0.10 & 3.30 \\
\hline
\end{tabular}

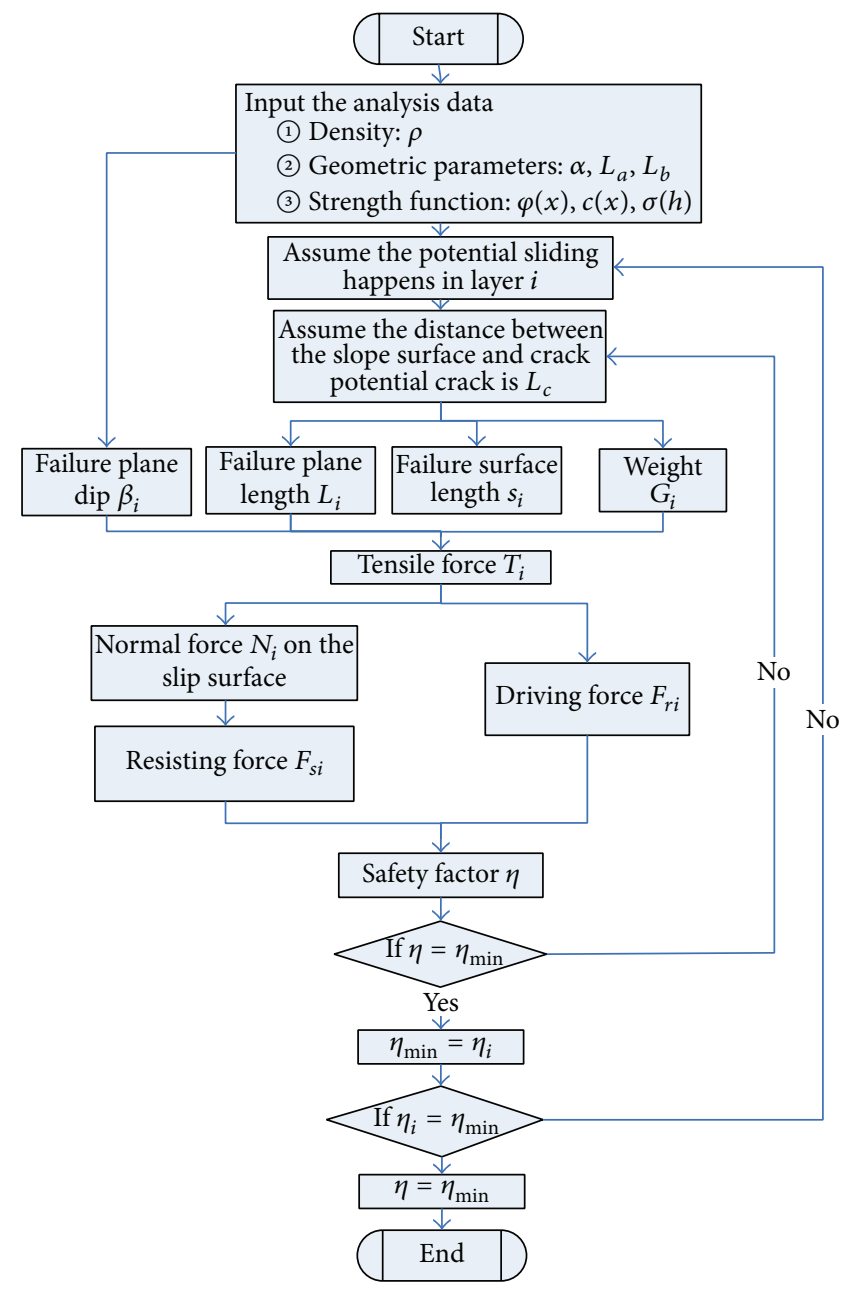

Figure 7: Flow chart of stability calculation for bedding rock slope.

\section{Discussion}

The spatial variation model of the rock mass and rock discontinuities discussed in this paper is based on S-curve model. It is appropriate for indicating the spatial variability of rock discontinuities shear strength parameters $c$ and $\varphi$ and the rock mass tensile strength $\sigma$ under the high weathering and excavation unloading. The strength of rock discontinuities near the upper slope surface is lower than deep inside part. If the resistance supplied by the tensile strength of rock mass is constant, the most unstable sliding surface is the bedding plane. However, the tensile strength and the length of the potential cracking surface are constantly changing, which makes the stability of rock slope more complicated. If this resistance force is lower than the sliding force, the safety factor along the bedding plane is consistently decreasing. With the tensile strength and the length of potential cracking surface increasing, the resistance force may make the safety factor decrease first and then increase.

In the modified limiting equilibrium equations, the spatial variations of the strength of rock discontinuities and rock mass are introduced in this method. If we set resistance supplied by the tensile strength of rock mass to zero, this calculation model will degenerate into an idealized model of planar failure. Note that this strength parameters model of the rock mass and rock discontinuities sometimes cannot 


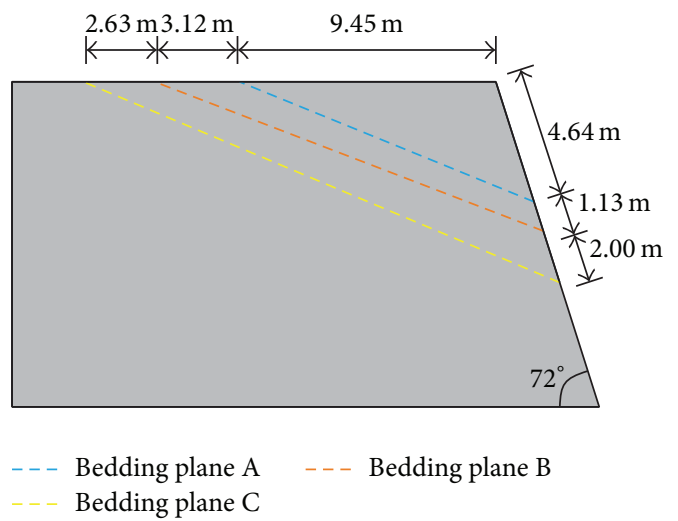

FIgURE 8: Analysis model of the case study.

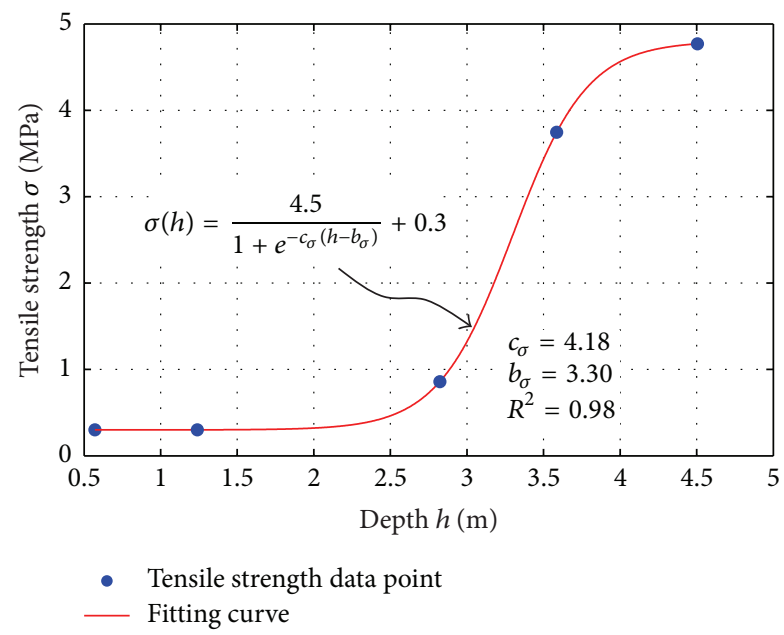

Figure 9: S-curve model for the tensile strength.

describe the spatial variability of strength parameters exactly. Nevertheless, the main idea for calculating the safety factor of stratified rock slope is still valid and needs to change the expression of strength parameters.

The sliding surface in a slope may consist of a single plane continuous over the full area of the surface or a complex surface made up of both discontinuities and fractures through intact rock [21]. Here, the sliding surface is composed of the bedding surface and vertical potential cracking surface. It is different from the failure mode caused by propagating cracks which are extended and coalesced with neighboring joints. The suggested method in this paper is appropriate for analyzing the stability of stratified rock slope whose joint crack is undeveloped.

\section{Conclusions}

The plane failure is one of the rock slope failure modes in field situations, and the limit equilibrium approach for the estimation of the factor of safety of the rock slope against plane failure has been well accepted by the engineers. In sedimentary rock mass, the stratified rock slope usually

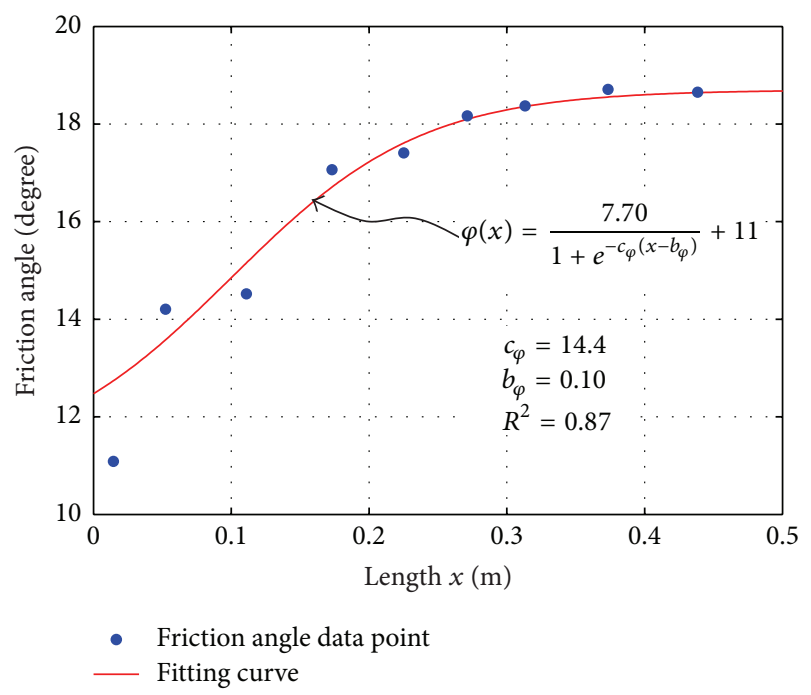

(a)

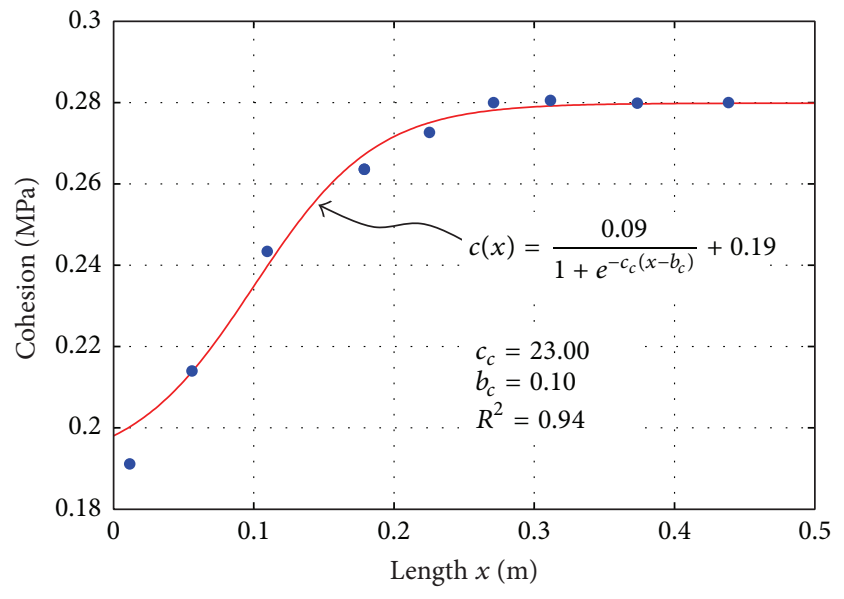

- Cohesion data point Fitting curve

(b)

FIGURE 10: S-curve model for the friction angle and cohesion of the rock discontinuities.

has several bedding planes whose dips and mechanical parameters have significant effects on rock mass strength and stability. However, previous limit equilibrium approaches were mainly about the plane failure mode with single sliding surface and failed to predict the stability of the rock slope with various bedding planes. This paper presented a modified limit equilibrium method for predicting the stability of the sedimentary rock slope with flat bedding planes. In this method, the spatial variations of shear strength parameters $c$ and $\varphi$ of bedding plane and the tensile strength $\sigma$ of rock mass were considered and they are expressed by the Scurve model. The potential tensile at the top of rock mass can also be considered in plane failure mode, incorporating various combinations of potential sliding surface and tensile crack. The critical sliding surface and the tensile crack were determined by finding the potential sliding surface which had 


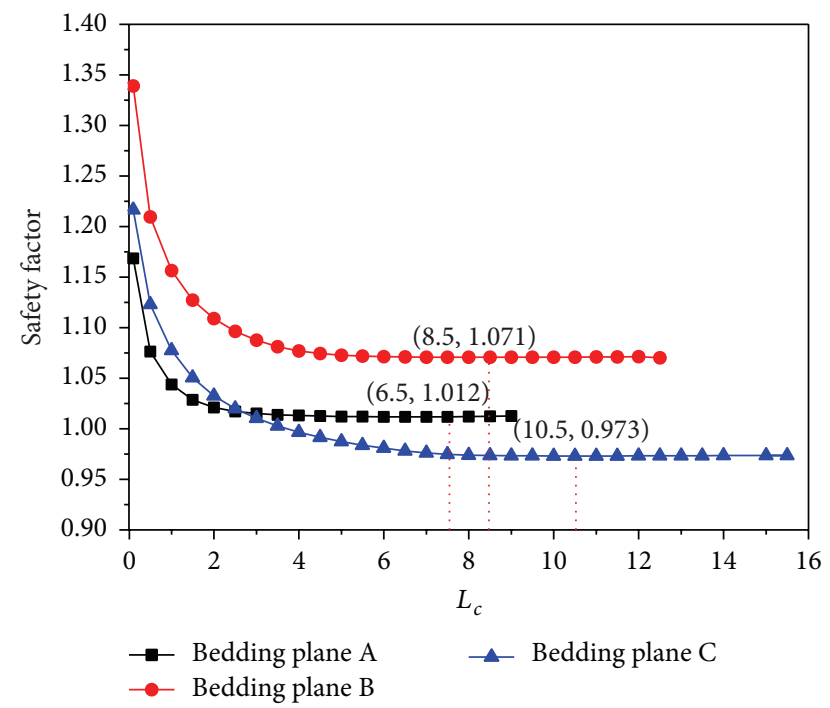

FIGURE 11: Relations between factor of safety and $L_{c}$.

the minimum factor of safety. This method was utilized in the stability analysis of a case study, in Three Gorges Reservoir Region, China. The factors of safety were different between the bedding planes, and they were affected by the resistance supplied by the tensile strength of rock mass. The factor of safety of the case study was 0.973 , the critical sliding surface appears at bedding plane $\mathrm{C}$, and the tension-controlled failure occurs at $10.5 \mathrm{~m}$ to the slope face. On the basis of generalized analytical expressions for the factor of safety, the example was provided to show the effectiveness of the modified limit equilibrium method in the stability analysis of stratified rock slopes.

\section{Competing Interests}

The authors declare that they have no competing interests.

\section{Acknowledgments}

This study was funded by National Natural Science Foundation of China (nos. 41427802, 41172292, 41302257, and 41502300), Zhejiang Provincial Natural Science Foundation (no. Q16D020005), and Zhejiang Provincial Natural Science Foundation (no. Q13D020001).

\section{References}

[1] Y. Zhao, Z.-Y. Tong, and Q. Lü, "Slope stability analysis using slice-wise factor of safety," Mathematical Problems in Engineering, vol. 2014, Article ID 712145, 6 pages, 2014.

[2] S. G. Du, Y. J. Hu, and X. F. Hu, "Measurement of joint roughness coefficient by using profilograph and roughness ruler," Journal of Earth Science, vol. 20, no. 5, pp. 890-896, 2009.

[3] S. K. Shukla and M. M. Hossain, "Analytical expression for factor of safety of an anchored rock slope against plane failure," International Journal of Geotechnical Engineering, vol. 5, no. 2, pp. 181-187, 2011.
[4] N. Sivakugan, S. K. Shukla, and B. M. Das, Rock Mechanics: An Introduction, CRC Press, New York, NY, USA, 2013.

[5] M. Gencer, "Progressive failure in stratified and jointed rock mass," Rock Mechanics and Rock Engineering, vol. 18, no. 4, pp. 267-292, 1985.

[6] J.-J. Dong, C.-H. Tu, W.-R. Lee, and Y.-J. Jheng, "Effects of hydraulic conductivity/strength anisotropy on the stability of stratified, poorly cemented rock slopes," Computers and Geotechnics, vol. 40, pp. 147-159, 2012.

[7] J. Ching, Z.-Y. Yang, J.-Q. Shiau, and C.-J. Chen, "Estimation of rock pressure during an excavation/cut in sedimentary rocks with inclined bedding planes," Structural Safety, vol. 41, pp. 1119, 2013.

[8] H. Tang, R. Yong, and M. A. M. Ez Eldin, "Stability analysis of stratified rock slopes with spatially variable strength parameters: the case of Qianjiangping landslide," Bulletin of Engineering Geology and the Environment, 2016.

[9] X.-L. Yang and J.-H. Yin, "Linear Mohr-Coulomb strength parameters from the non-linear Hoek-Brown rock masses," International Journal of Non-Linear Mechanics, vol. 41, no. 8, pp. 1000-1005, 2006.

[10] P. Fortsakis, K. Nikas, V. Marinos, and P. Marinos, "Anisotropic behaviour of stratified rock masses in tunnelling," Engineering Geology, vol. 141-142, pp. 74-83, 2012.

[11] E. Hoek and J. D. Bray, Rock Slope Engineering, CRC Press, 1981.

[12] S. Sharma, T. K. Raghuvanshi, and R. Anbalagan, "Plane failure analysis of rock slopes," Geotechnical and Geological Engineering, vol. 13, no. 2, pp. 105-111, 1995.

[13] E. B. Kroeger, "Analysis of plane failures in compound slopes," International Journal of Surface Mining, Reclamation and Environment, vol. 14, no. 3, pp. 215-222, 2000.

[14] B. S. Jiang, M. F. Cai, and H. Du, "Analytical calculation on stability of slope with planar failure surface," Chinese Journal of Rock Mechanics and Engineering, vol. 23, no. 1, pp. 91-94, 2004.

[15] M. Ahmadi and M. Eslami, "A new approach to plane failure of rock slope stability based on water flow velocity in discontinuities for the Latian dam reservoir landslide," Journal of Mountain Science, vol. 8, no. 2, pp. 124-130, 2011.

[16] A. Johari, A. Fazeli, and A. A. Javadi, "An investigation into application of jointly distributed random variables method in reliability assessment of rock slope stability," Computers and Geotechnics, vol. 47, pp. 42-47, 2013.

[17] H. A. Viles, "Linking weathering and rock slope instability: nonlinear perspectives," Earth Surface Processes and Landforms, vol. 38, no. 1, pp. 62-70, 2013.

[18] H. M. Tang, Z. X. Zou, C. R. Xiong et al., "An evolution model of large consequent bedding rockslides, with particular reference to the Jiweishan rockslide in Southwest China," Engineering Geology, vol. 186, pp. 17-27, 2015.

[19] Z. X. Zou, H. M. Tang, C. R. Xiong, Y. P. Wu, X. Liu, and S. B. Liao, "Geomechanical model of progressive failure for large consequent bedding rockslide and its stability analysis," Chinese Journal of Rock Mechanics and Engineering, vol. 31, no. 11, pp. 2222-2230, 2012 (Chinese).

[20] Z. T. Bieniawski and I. Hawkes, "Suggested methods for determining tensile strength of rock materials," International Journal of Rock Mechanics and Mining Sciences, vol. 15, no. 3, pp. 99-103, 1978.

[21] C. W. Duncan and W. M. Christopher, Rock Slope EngineeringCivil and Mining, Taylor \& Francis, New York, NY, USA, 4th edition, 2005. 


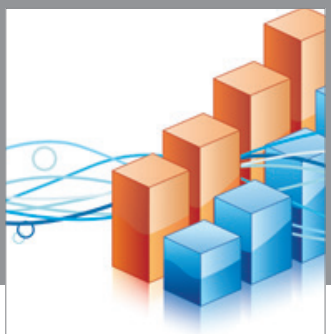

Advances in

Operations Research

vatem alat4

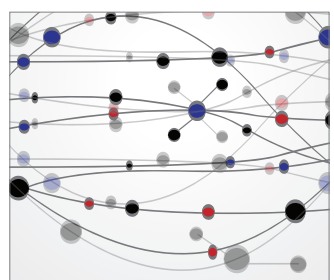

\section{The Scientific} World Journal
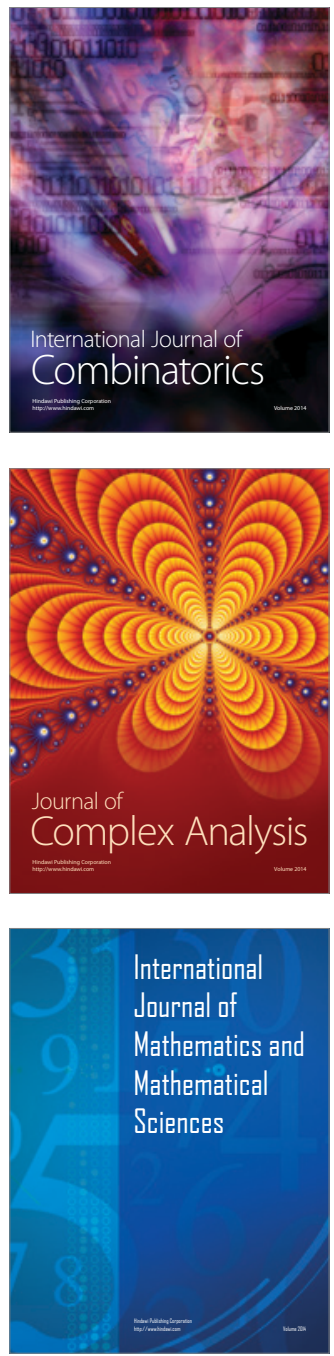
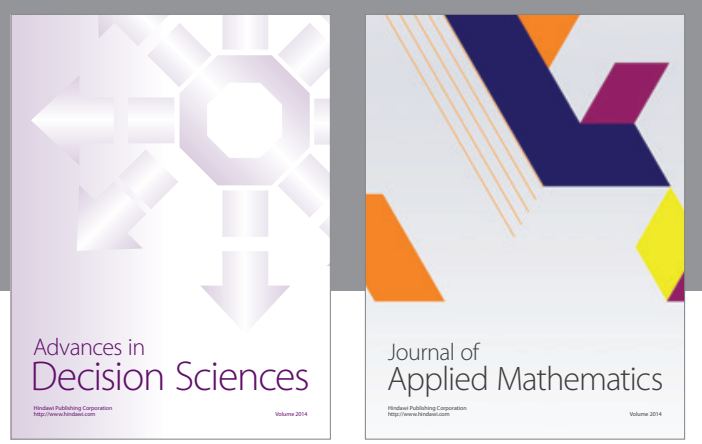

Algebra

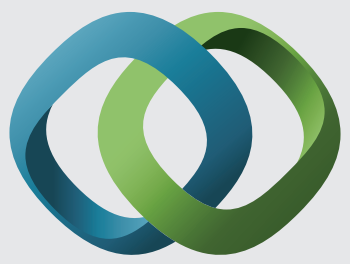

\section{Hindawi}

Submit your manuscripts at

http://www.hindawi.com
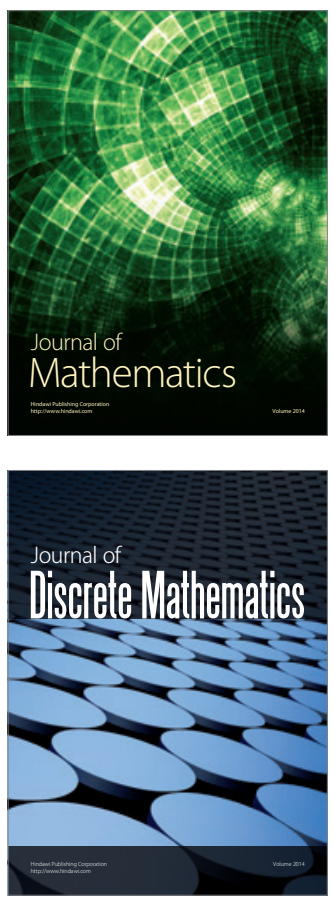

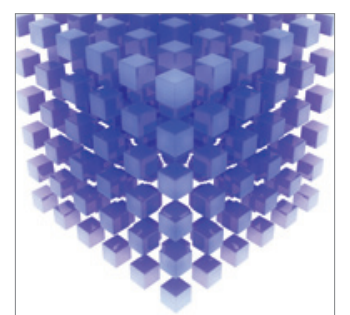

Mathematical Problems in Engineering
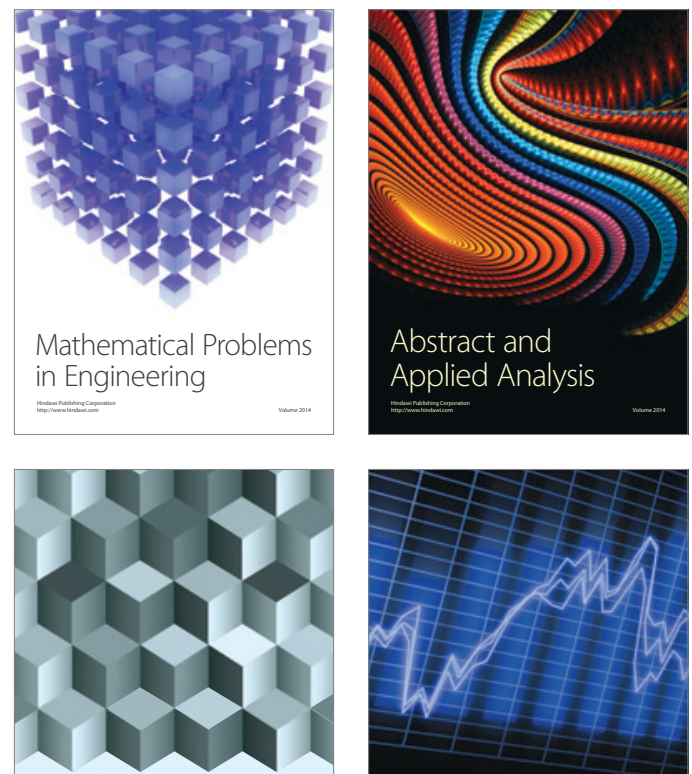

Journal of

Function Spaces

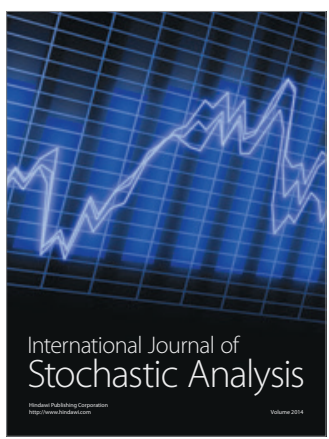

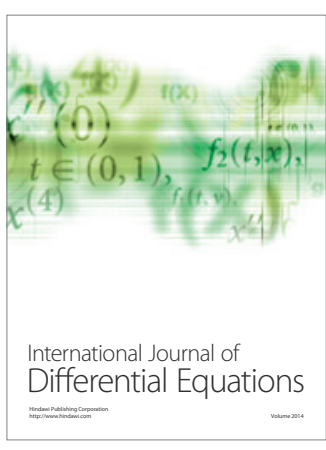
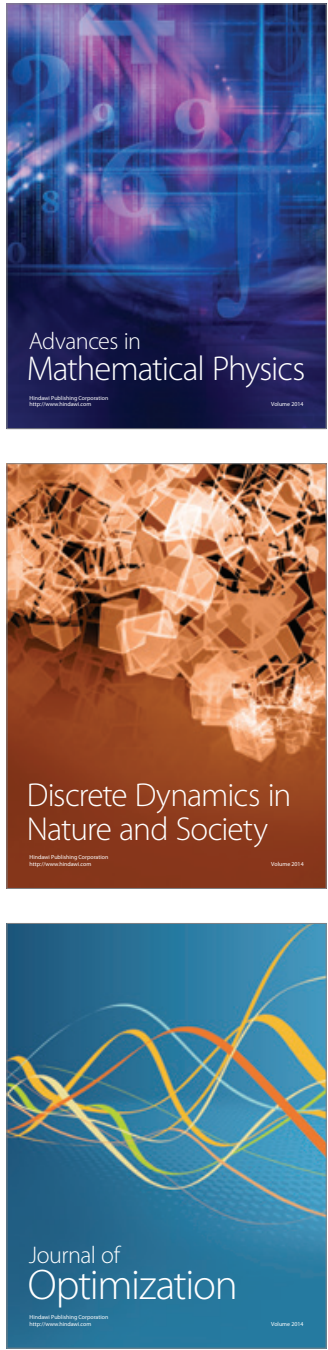